\title{
Comparison of the effectiveness of compression stockings and layer compression systems in venous ulceration treatment
}

Maria T. Szewczyk ${ }^{1,2}$, Arkadiusz Jawień2, Katarzyna Cierzniakowska ${ }^{1,2}$, Justyna Cwajda-Białasik ${ }^{1}$, Paulina Mościcka²

1Department of Surgery Nursing, Ludwik Rydygier Collegium Medicum in Bydgoszcz, Nicolaus Copernicus University in Torun, Poland

2Department of Surgery, Ludwik Rydygier Collegium Medicum in Bydgoszcz, Nicolaus Copernicus University in Torun, Poland

Submitted: 9 February 2010

Accepted: 11 March 2010

Arch Med Sci 2010; 6, 5: 793-799

DOI: 10.5114/aoms.2010.17097

Copyright @ 2010 Termedia \& Banach

\section{Abstract}

Introduction: The aim of the research was to compare the dynamics of venous ulcer healing when treated with the use of compression stockings as well as original two- and four-layer bandage systems.

Material and methods: A group of 46 patients suffering from venous ulcers was studied. This group consisted of $36(78.3 \%)$ women and $10(21.70 \%)$ men aged between 41 and 88 years (the average age was 66.6 years and the median was 67). Patients were randomized into three groups, for treatment with the ProGuide two-layer system, Profore four-layer compression, and with the use of compression stockings class II. In the case of multi-layer compression, compression ensuring $40 \mathrm{mmHg}$ blood pressure at ankle level was used.

Results: In all patients, independently of the type of compression therapy, a few significant statistical changes of ulceration area in time were observed (Student's $t$ test for matched pairs, $p<0.05$ ). The largest loss of ulceration area in each of the successive measurements was observed in patients treated with the four-layer system - on average $0.63 \mathrm{~cm}^{2} /$ per week. The smallest loss of ulceration area was observed in patients using compression stockings - on average $0.44 \mathrm{~cm}^{2} /$ per week. However, the observed differences were not statistically significant (Kruskal-Wallis test $\mathrm{H}=4.45, p>0.05$ ).

Conclusions: A systematic compression therapy, applied with preliminary blood pressure of $40 \mathrm{mmHg}$, is an effective method of conservative treatment of venous ulcers. Compression stockings and prepared systems of multi-layer compression were characterized by similar clinical effectiveness.

Key words: compression therapy, bandage systems, compression stockings, venous ulcer.

\section{Introduction}

Research concerning treatment as well as everyday life of patients suffering from ulcers show that ulcers still constitute a serious therapeutic problem and they make biopsychosocial functioning very difficult [1, 2]. According to the current model of chronic wound healing, eradication of the factors responsible for wound development determines the effectiveness of therapy and thus should constitute its main component.

\author{
Corresponding author: \\ Maria T. Szewczyk, MD, PhD \\ Department of Surgery \\ Ludwik Rydygier Collegium \\ Medicum in Bydgoszcz \\ Nicolaus Copernicus University \\ in Torun \\ ul. Ujejskiego 75 \\ 85-168 Bydgoszcz, Poland \\ Phone: +48523655232 \\ Fax: +4852365 5782 \\ E-mail: mszewczyk@cm.umk.pl
}


In the case of ulcers of venous aetiology, compression therapy has been called "the gold standard of wound healing". The results of scientific research confirm its effectiveness [1-6] and teams of experts recommend using compression with the aim of counteracting oedema and other harmful effects of venous hypertension [7-13]. It is thought that compression, used according to the instructions, can minimize and even reverse dermal and vascular changes accompanied by chronic venous failure.

Achieving effects comparable with permanent surgical removal of inefficient superficial and/or perforating veins demands a long-lasting and consistent use of compression. Among the majority of patients, this means practising compression therapy throughout life.

In venous ulceration treatment, various specialist bandages, compression stockings and pre-prepared compression systems are used. These particular forms differ in physicochemical structure of the material from which they are made, as well as the way they influence the tissues. This characteristic features of the material as well as its elasticity and stretchability determine the value of intersuperficial pressure, marching and resting pressure. Materials which include a lot of elastomeric (longstretch) fibres have better ability to keep the primal tension and pressure under a dressing. They provide high resting pressure but they must be removed at night. Materials which are not elastic (shortstretch), although they do not demand frequent replacements and they can be left on a limb for several days, lose their primal tension very quickly and they cause the decrease of pressure under a dressing. However, the advantage of short-stretch materials is the ability to generate high active pressures and prevention of limb swelling while oedema occurs [14, 15]. Blair et al. [20] suggested a four-layer (4LB) compression system. The authors pointed out that layer compression, in comparison with simple, elastic dressings, demonstrates significantly higher efficiency in the treatment of venous ulcers. It also maintains relatively steady pressure under the bandage [20]. At present, bandage sets for multi-layer application are available on the market. Two- and four-layer compression is commonly used. In Poland there is a lack of research comparing the efficiency of various compression sets. In the present study the effectiveness of three types of compression therapy was analysed.

The aim of the research was to compare the dynamics of ulcer healing when treated with the use of compression stockings as well as two original bandage systems: the two-layer ProGuide and fourlayer Profore.

\section{Material and methods}

The research was carried out between 2007 and 2008 at the Ulcer Healing Clinic of the General Surgery Clinical Ward of Jan Biziel Provincial Hospital in Bydgoszcz. All patients, suffering from ulcers and who visited the clinic because of that, were assessed according to the inclusion criteria. These criteria were met by the following patients: men and non-pregnant women under 18 years old who suffered from lower leg ulcers of venous aetiology confirmed with the help of ultrasound examination (duplex scan). The patients had a value of ankle-arm index from 0.9 to 1.3. The maximum ulceration area was $15 \mathrm{~cm}^{2}$. Patients with the following conditions were excluded from the research: those with ulceration area greater than $15 \mathrm{~cm}$, those with a mixed aetiology or a nonvenous one, those suffering from diabetes or atherosclerotic disease of lower limbs, those suffering from arterial hypertension, cardiovascular insufficiency, rheumatoid arthritis (RA) and other diseases of autoimmunological origin. Those who visited the clinic unsystematically were excluded from the research.

The patients ( $n=46$ ) who met the inclusion criteria were randomized into three groups:

Group 1 - 15 patients treated with elastic compression class II in the form of "Maxis" kneelength compression stockings (PPH Real). The stockings were chosen individually, after measurement of the patient's limbs: the length from the foot to the under-knee area as well as the size under the knee in the fattest place of the calf and in the narrowest place above the ankle. The measurements were taken after a 30-minute rest of the patient with the limb raised above heart level. The patients who were using the stockings were instructed about the rules of their usage.

Group 2-16 patients treated with two-layer ProGuide ${ }^{\circledR}$ (Smith \& Nephew) compression (cotton wool and cotton band plus compression bandage [short-stretch]).

Group 3-15 patients treated with four-layer Profore $^{\circledR}$ (Smith \& Nephew) compression (cotton wool and cotton band, crepe bandage, elasticated bandage - long-stretched, cohesive bandage). The bandage compression was applied by a qualified and trained nurse. The bandages were replaced twice a week during the patient's visit to the Ulcer Healing Clinic. The bandages were applied from the metatarsus to the head of the fibula. The spiral technique was used, keeping $50 \%$ space while applying the bandage rolls. Next layers of the dressing were applied in the opposite direction. The intra-surface pressure was measured at ankle level (the required value was $40 \mathrm{mmHg}$ ) as well as at the widest part of the calf (the required value was $20 \mathrm{mmHg}$ ) In order to measure intra-surface pressure 
a Japanese appliance, Kikuhime, was used. Compression stockings ensured II class compression.

Independently of the form of compression therapy, among all the patients, local treatment of ulceration was carried out according to the T.I.M.E. strategy [16] including: hydrotherapy and mechanical wound care, washing the limb and skin around the ulceration as well as greasing the skin around the wound. Depending on the assessment and characteristics, the ulceration was protected with foam and hydrocolloid dressings.

The measurement of ulceration area was conducted electronically using a Visitrac appliance and was taken every two weeks using the planimetry method. The maximum time of observation was 12 weeks. Among all patients, a general method of assessment by points was used. This assessment showed the progression level of chronic venous insufficiency according to CEAP, $C_{6}$. This name comes from first letters of the following words: Clinical (signs), Etiological (classification), Anatomical (distribution), Pathophysiological (dysfunction). Clinical classification (C) presents the increasing progression of venous disorders. $\mathrm{C}_{6}$, an active ulceration, was assigned to objective symptoms [17]. Point values were assigned from " 0 " to " 2 " (the hardest state of scale parameter). Eight parameters were assessed: pain, oedema, skin melanosis, lipodermatosclerosis, ulceration area, time of its presence, recurrence, and number of ulcers. Patients could achieve a maximum of 16 points. The general assessment of scale parameters was carried out in the first and the last week of the research.

The consent of the Bioethics Commission of the Nicolaus Copernicus University in Torun, Ludwik Rydygier Collegium Medicum in Bydgoszcz was obtained. The patients gave their written consent to participate in the research.

The results of the research were analysed based on statistical methods. The basic descriptive statistics were determined. The significance of differences between the compared groups was analysed using the non-parametric Kruskal-Wallis test. This test serves to compare more than two groups and it rejects the null hypothesis when $\mathrm{H}\left(\mathrm{H}^{\prime}\right)$ $>\chi_{\alpha, k-1}^{2}$. The significance of differences within the same group was tested using paired Student's $t$ test. This test serves to analyse the differences between the averages for matched pairs. The significance of differences is estimated for numerous degrees of freedom, d.f. $=\mathrm{N}-1$.

\section{Results}

\section{Characteristics of the study group}

Forty-eight patients meeting inclusion criteria were qualified for the study. In the end, 46 of them were randomized into three groups of compression therapy ( 2 patients were excluded because of lack of regularity of visits to the clinic). The statistical analysis showed homogeneity of study groups in terms of age, sex, initial ulceration area and the initial value of CEAP; C-6 score. The characteristics of the analysed groups are presented in Table I.

We compared the dynamics of ulcer healing of patients treated with different types of compression therapy. The changes of ulceration area were statistically significant regardless of the type of compression therapy. During the first two weeks of treatment the ulceration area decreased on average by $1.01 \mathrm{~cm}^{2} /$ per week, during the next two weeks by $0.94 \mathrm{~cm}^{2} /$ per week, and after eight weeks by $0.56 \mathrm{~cm}^{2} /$ per week. The average loss of ulceration area during the whole 12-week observation period was $0.42 \mathrm{~cm}^{2} /$ per week $\left(t_{\text {par }}=6.28, p<0.001\right)$. A slightly higher percentage loss of ulceration area was observed on patients treated with two-layer ProGuide compression system. The smallest loss of ulceration area was observed in patients who used compression stockings. The difference in proportion of healed area of patients treated with different types of compressions was successively: after 2 weeks $1.3-8.7 \%$, after 4 weeks $4.3-16.2 \%$, after 8 weeks $8.6-17 \%$, and after 12 weeks $4.2-15 \%$. However, greater dynamics of healing was observed in patients treated with the four-layer Profore system - the average loss of area during the whole 12-week observation period was $0.63 \mathrm{~cm}^{2} /$ per week. The value of the same parameter in patients treated with the two-layer ProGuide compression system was $0.55 \mathrm{~cm}^{2} /$ per week and of those treated with compression stockings $0.44 \mathrm{~cm}^{2} /$ per

Table I. Comparable characteristics of patients treated with Maxis compression stockings and ProGuide two-layer and Profore four-layer compression systems

\begin{tabular}{|lcccc|}
\hline Variables & $\begin{array}{c}\text { Compression stockings } \\
(n=15)\end{array}$ & $\begin{array}{c}\text { ProGuide }(n=16) \\
\text { II-layer }\end{array}$ & $\begin{array}{c}\text { Profore }(n=15) \\
\text { IV-layer }\end{array}$ & $\begin{array}{c}\text { Significance of } \\
\text { differences }\end{array}$ \\
\hline Sex F : M & $13(86.7 \%): 2(13.3 \%)$ & $12(75 \%): 4(25 \%)$ & $11(73.3 \%): 4(26.7 \%)$ & $p>0.05$ \\
\hline Age [years] $(\mathrm{x} \pm \mathrm{SD})$ & $66.4 \pm 9.22$ & $67.5 \pm 9.03$ & $65.9 \pm 9.24$ & $p>0.05$ \\
\hline Ulceration area $\left[\mathrm{cm}^{2}\right.$ ] $(\mathrm{x} \pm \mathrm{SD})$ & $4.7 \pm 4.18$ & $5.3 \pm 3.93$ & $6.0 \pm 3.98$ & $p>0.05$ \\
\hline Initial CEAP score $(\mathrm{x} \pm \mathrm{SD})$ & $11.9 \pm 1.12$ & $11.2 \pm 1.3$ & $12.6 \pm 1.4$ & $p>0.05$ \\
\hline
\end{tabular}

F-females, $M$-males 


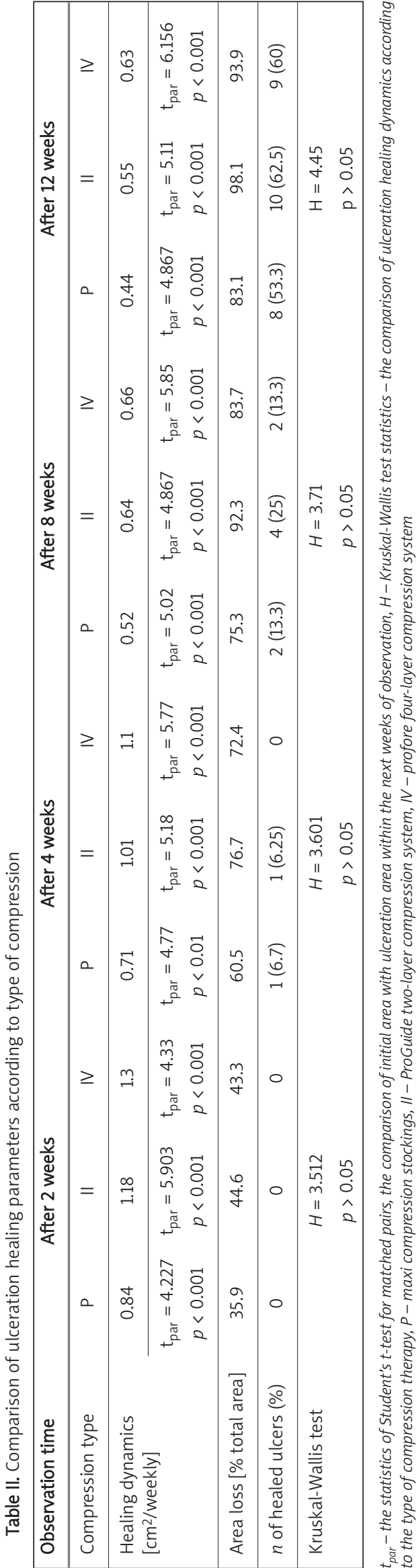

week. Although the changes of ulceration area in each analysed group were statistically significant $(p<0.001)$, inter-group differences were not found $(H=4.45, p>0.05)$. What is more, no statistically significant advantage of any of the applied types of compression therapy was found (Table II). In the group of patients who used Maxis compression stockings complete healing was achieved in $8(53.3 \%)$ ulcerations, in the groups of patients treated with layer compression systems, complete healing was achieved in 10 (62.5\%) ulcerations treated with the two-layer compression system and $9(60 \%)$ ulcerations treated with the four-layer compression system. The differences were statistically significant $(p>0.05)$.

Together with the progress in ulceration healing, statistically significant changes in CEAP scoring values (Table III) were observed. The difference in average CEAP C- 6 score of all patients was 3.6 points and was statistically significant $(p<0.001)$. Also, in groups of patients divided according to the type of compression therapy, the differences in CEAP scoring values were statistically significant; they gained 3.5 points among patients who used compression stockings, 3.5 points among patients treated with the ProGuide system, and 4.3 points among patients treated with the Profore system. The statistical analysis did not reveal any statistically significant intra-group differences (Kruskal-Wallis test $\mathrm{H}=3.102, p>0.05$ ).

\section{Discussion}

A systematic review of the literature demonstrates that every type of correctly applied compression significantly improves healing of venous ulceration and it is difficult to state which method is the most effective [4]. In some of the research we can notice the superiority of multi-layer systems over one-layer compression [18-20]. In other research, the effectiveness of the investigated methods was found comparable and the differences statistically insignificant [2, 21-23]. Extensive research comparing the effectiveness of multi-layer systems with short-stretch compression did not show statistically relevant differences. In one of the first studies of four-layer compression effectiveness Blair et al. [20] after 12 weeks of observation achieved $74 \%$ healing of large ulcerations (the initial average area was $15.4 \mathrm{~cm}^{2}$ ) which had been treated ineffectively before using one-layer elastic bandages. The results of the next research [21-23] showed lower, but satisfactory rates. It was suggested that four-layer compression is as effective as two-layer (short-stretch) compression. The occurrence, in some research, of superiority of one type over another, was explained as different experience of people applying the compression. There were also some differences in important 
Table III. Analysis of CEAP score values according to the type of compression

\begin{tabular}{|c|c|c|c|c|c|c|}
\hline \multirow{3}{*}{$\begin{array}{l}\text { Type of compression } \\
\text { CEAP score value } \\
\text { (before and after the research) }\end{array}$} & \multicolumn{2}{|c|}{ Stockings } & \multicolumn{2}{|c|}{ ProGuide } & \multicolumn{2}{|c|}{ Profore } \\
\hline & before & after & before & after & before & after \\
\hline & 11.7 & 8.2 & 11.25 & 7.75 & 12.6 & 8.3 \\
\hline \multirow{2}{*}{ test $t_{\text {par }}$ statistics } & \multicolumn{2}{|c|}{$t_{\mathrm{par}}=11.16$} & \multicolumn{2}{|c|}{$t_{\mathrm{par}}=10.63$} & \multicolumn{2}{|c|}{$t_{p a r}=11.72$} \\
\hline & \multicolumn{2}{|c|}{$p<0.001$} & \multicolumn{2}{|c|}{$p<0.001$} & \multicolumn{2}{|c|}{$p<0.001$} \\
\hline $\begin{array}{l}\text { CEAP score value } \\
\text { (before and after the research) }\end{array}$ & \multicolumn{4}{|c|}{ CEAP before -11.9} & $r-8.3$ & \\
\hline test $t_{\text {par }}$ statistics & \multicolumn{6}{|c|}{$t_{\mathrm{par}}=15.64(p<0.001)$} \\
\hline Kruskal-Wallis test & \multicolumn{6}{|c|}{$H=3.102(p>0.05)$} \\
\hline
\end{tabular}

$t_{\text {par }}$ - $t$-test statistics for matched pairs - comparison of the initial CEAP score with the final score (after 12 weeks observation), $H$ - Kruskal-Wallis test statistics - the comparison of CEAP score changes according to the type of compression therapy, II - ProGuide two-layer compression system, IV-profore four-layer compression system

prognostic factors of ulceration healing, among others, ulceration initial area [4].

In our own research, the comparison of two preprepared Profore and ProGuide compression systems as well as elastic compression, that is to say, compression stockings, did not show statistically significant differences. However, in layer compression, faster healing dynamics and a higher percentage of healed area than in the case of using stockings were observed. The observed differences were statistically significant. Moreover, in all studied groups the number and the percentage of healed ulcerations were similar. In Stacey et al. research [24], which compares the effectiveness of compression stockings with alginate dressing, the dynamics of ulceration healing of patients wearing these stockings was similar to that observed in our own research. To compare, Callam et al. [25], who assessed the effectiveness of elastic and inelastic compression of patients with ulceration of similar average initial area, reported the superiority of elastic compression.

During the 12-week therapy, statistically significant differences of healed ulcerations were achieved $-4 \%$ and $28 \%$ ( $p<0.01)$. Larsen et al. suggest [14] that elastic material, both in the form of stockings and bandages, is characterized by better ability to keep stable values of pressure in time. Inelastic material, on the other hand, loses its primal tension very quickly, although if it is frequently changed it can also be effective, especially in active patients. In our own research, the bandage was changed at least twice a week. The achieved rates of healing, that is $62.2 \%$ and $60 \%$ of ulcerations as well as $98.1 \%$ and $93.9 \%$ of ulceration area loss after 12 weeks of compression therapy, suggest that this frequency of changing dressings is sufficient when the ulceration oozing is either slight or medium. The elements of layer systems, applied with the initial pressure $40 \mathrm{mmHg}$, ensure effective intra-surface compression, even after some decrease of blood pressure, in time. Partsch et al. [26, 27] emphasise that in order to achieve a significant improvement of haemodynamics in the venous system, compression pressure should increase while the patient is walking. Peak working pressure should be higher than venous pressure. The same authors [22, 28] reported that at the same intra-surface pressure values, short-stretch bandages are more efficient than elastic ones. They generate higher working pressure. Four-layer systems are similar to shortstretch bandages in terms of efficiency. They reduce venous reflux in the deep vein system. What is more, Polignano et al. [21] concluded that Profore sets of four-layer compression are similar to shortstretch compression in terms of efficiency.

The authors emphasize that characteristics of single compression materials change after putting them on in a compression layer system. In the study by Ruckley et al. [15] it was found that each of four sets of four-layer compression systems (Profore ${ }^{\circledR}$, Ultra Four ${ }^{\circledR}$, K-Four $^{\circledR}$ and System $4^{\circledR}$ ) regardless of similar physical properties generated characteristically different pressures. This concerned each of the bandage layers as well as the cumulative value generated by the whole system. The differences in average final pressures ranged from $3 \mathrm{mmHg}$ to $10 \mathrm{mmHg}$. The authors suggested that applying any type of compression without intrasurface pressure control is a mistake and can give inconsistent therapeutic effects. Moreover, Partsch et al. [26-28] in many works demonstrated that in order to achieve a substantial haemodynamic improvement, it is important to apply compression with the appropriate intra-surface pressure.

In our own research, the intra-surface pressure was controlled. The prepared two-and four-layer compression systems were applied in such a way that the initial pressure, under the dressing, was 
$40 \mathrm{mmHg}$ at ankle level and about $20 \mathrm{mmHg}$ at the widest part of the lower leg. The patients who used compression stockings achieved compression of class II and the values of pressures were similar. It is possible that this fact explains the comparable effectiveness of studied methods. Pressure of $40 \mathrm{mmHg}$ is an effective value which is also recommended by experts.

In the presented research, during 12 weeks from applying compression therapy, in all three groups CEAP; C6 clinical symptoms decreased $\left(t_{\text {par }}=15.64\right.$, $p<0.001)$. The results of our research as well as data from the literature, describing the effectiveness of different types of compression therapy, show that they have an important influence on the venous ulceration healing process. However, it is difficult to determine decisively which of the available methods of compression therapy should be recommended as the most effective one.

In conclusions, a regular compression therapy which is applied with the initial pressure of $40 \mathrm{mmHg}$ at ankle level and compression stockings of class II is an effective method of venous ulceration conservative treatment. The prepared systems of layer compression are applied with control of the intra-surface pressure and the ready compression products of class II are characterized by similar effectiveness of lower leg venous ulceration treatment. Ensuring optimum values of intra-surface pressure depends on adjusting and applying the compression therapy. Each of the methods may be efficient provided that it is used correctly and systematically.

\section{Acknowledgments}

The original compression systems, compression stockings and dressings used in the research were fully financed out of university funds to be used for statutory research.

\section{References}

1. Jawień A, Szewczyk MT, Kędziora-Kornatowska K, et al. Functional and biopsychosocial restrictions among patients with a venous ulcer. Arch Med Sci 2006; 2: 36-41.

2. Barwell J, Davies CE, Deacon J, et al. Comparison of surgery and compression with compression alone in chronic venous ulceration (ESCHAR study): randomized controlled trial. Lancet 2004; 363: 1854-9.

3. Guest M, Smith JJ, Tripuraneni G, et al. Randomized clinical trial of varicose vein surgery with compression versus compression alone for the treatment of venous ulceration. Phlebology 2003; 18: 130-6.

4. Kramer SA. Compression wraps for venous ulcer healing: a review. J Vasc Nurs 1999; 17: 89-97.

5. Franks PJ, Moody M, Moffat CJ, et al. Randomised trial of cohesive short stretch versus four layer bandaging in the management of chronic venous ulceration. Wound Repair Regen 2004; 12: 157-62.
6. Moffat CJ, McCullagh L, O'Connor T, Doherty DC. Randomized trial of four-layer and two-layer bandage systems in management of chronic venous ulceration. Wound Repair Regen 2003; 11: 166-71.

7. Consensus statement. Indications for compression therapy in venous and lymphatic disease. Consensus based on experimental data and scientific evidence. Under the auspices of the IUP. Int Angiol 2008; 27: 193-219.

8. Szewczyk MT, Jawień A. Zalecenia specjalistycznej opieki pielęgniarskiej nad chorym z owrzodzeniem żylnym goleni [Polish]. Pielęgniarstwo Chirurgiczne i Angiologiczne 2007; 3: 95-129.

9. Jawień A, Rybak Z, Cencora A, et al. Wytyczne Polskiego Towarzystwa Leczenia Ran w sprawie gojenia owrzodzeń żylnych goleni [Polish]. Leczenie Ran 2006; 3: 103-12.

10. Stücker M. Cutaneous microcirculation in skin lesions associated with chronic venous insufficiency. Dermatol Surg 1995; 21: 877-82.

11. Butler CM, Coleridge S: Microcirculatory aspects of venous ulceration. J Dermatol Surg Oncol 1994; 20: 474-80.

12. Roberts G, Hammand L, Collins C, et al. Some effects of sustained compression on ulcerated tissue. Angiology 2002; 53: 451-6.

13. Partch $\mathrm{H}$. Understanding the pathophysiological effects of compression. Position Document. EWMA 2003; 3: 2-4.

14. Larsen AM, Guttrup I. Watch the pressure - it drops! EWMA 2004; 4: 8-12.

15. Dale JJ, Ruckley CV, Gibson B, Brown D, Lee AJ, Prescott RJ. Multi-layer compression: comparison of four different four-layer bandage systems applied to the leg. Eur J Vasc Endovasc Surg 2004; 27: 94-9.

16. Moffatt C, Morison MJ, Pina E. Wound bed preparation for venous leg ulcers. Position Document EWMA. NEP LTD, 2004; 12-17.

17. Eklof B, Rutherford RB, Bergan JJ, et al. Revision of the CEAP classification for chronic venous disorders: consensus statement. J Vasc Surg 2004; 40. 1248-52.

18. Duby T, Hoffman D, Cameron J, et al. A randomized trial In the treatment of venous leg ulcers comparing the short stretch bandages, four layer bandage system and a long stretch-paste bandage system. Wounds 1993; 5: 276-9.

19. Nelson EA. Compression bandaging in the treatment of venous ulcers. J Wound Care 1996; 5: 415-8.

20. Blair S, Wrigth D, Blackhouse C, et al. Sustained compression and healing of chronic venous ulcers. BMJ 1988; 298: 1159-61.

21. Polignano R, Bonadeo P, Gasbarro S, et al. Randomised controlled study of four-layered compression vs. Unna's Boot for venous ulcers. J Wound Care 2004; 13: 21-4.

22. Partsch H, Damstra RJ, Tazelaar DJ, et al. Multicentre, randomised controlled trial of four layer bandaging versus short-stretch bandaging in the treatment of venous leg ulcers. Vasa 2001; 30: 108-13.

23. Scriven JM, Taylor LE, Wood AJ, et al. A prospective randomized trial of four layer versus shrot stretch compression bandages for the treatment of venous leg ulcers. Ann R Coel Surg Engl 1998; 80: 215-20.

24. Stacey M, Jopp-Mckay A, Rashid P, et al. The influence of dressings on venous ulcer healing - a randomised trial. J Wound Care 1997; 2: 62-8.

25. Callam MJ, Harper DR, Dale JJ, et al. Lothian and Forth Valley leg ulcer healing trial. Part 1: elastic versus nonelastic bandaging in the treatment of chronic leg ulceration. Phlebology 1992; 7: 136-41.

26. Partsch B, Partsch $\mathrm{H}$. Calf compression pressure required to achieve venous closure from supine to standing positions. J Vasc Surg 2005; 42: 734-8. 
27. Partsch $\mathrm{H}$. Improvement of venous pumping function in chronic venous insufficiency by compression depending on pressure and material. Vasa 1984;13: 58-64.

28. Partsch H, Menzinger G, Mostbeck A. Inelastic leg compression is more effective to reduce deep venous refluxes than elastic bandages. Derm Surg 2001; 25: 695-700. 